\title{
Biomechanics of Competitive Swimming Strokes
}

\author{
Tiago M. Barbosaㄹ, Daniel A. Marinho², \\ Mário J. Costa ${ }^{3}$ and António J. Silva ${ }^{4}$ \\ ${ }_{1}^{1}$ Polytechnic Institute of Bragança/CIDESD \\ ${ }^{2}$ University of Beira Interior/CIDESD \\ ${ }^{3}$ Polytechnic Institute of Bragança/CIDESD \\ ${ }^{4}$ University of Trás-os-Montes and Alto Douro/CIDESD \\ Portugal
}

\section{Introduction}

Competitive swimming is one of the most challenging sports to perform scientific research. Not only the research of human movement is quite complex, because human beings are not so determinists as other (bio)mechanical systems; but also, assessing human beings in aquatic environment becomes even more as this is not their natural environment and other physical principles have to be considered.

On regular basis, for human movement analysis, including the ones made on aquatic environments, experimental and numerical methods are used. Experimental methods are characterized by attaching bio-sensors to the subjects being analyzed, acquiring the biosignal and thereafter processing it. Numerical methods are characterized by the introduction of selected input data, processing data according to given mechanical equations and thereafter collecting the output data. Both methods groups aim to perform kinematics analysis, kinetics analysis, neuromuscular analysis and anthropometrical/inertial analysis.

These method groups are also used for biomechanical analysis of competitive swimming. A swimming event can be decomposed in four moments or phases: (i) the starting phase; (ii) the swimming phase; (iii) the turning phase and; (iv) the finishing phase. During any swimming event, a swimmer spends most of his/her absolute or relative time in the swimming phase. Therefore, the swimming phase is the most (but not the only one) determinant moment of the swimming performance. In this sense, a large part of the biomechanical analysis of competitive swimming is dedicated to the four competitive swimming strokes: (i) the Front Crawl; (ii) the Backstroke; (iii) the Breaststroke and; (iv) the Butterfly stroke.

The aim of this chapter has two folds: (i): to perform a biomechanical characterization of the four competitive swimming strokes, based on the kinematics, kinetics and neuromuscular analysis; (ii) to report the relationships established between all the domains and how it might influence the swimming performance. 


\section{Competitive swimming strokes kinematics}

Consistent swimming research started in the seventies. There is a significant increase on the scientific production about competitive swimming throughout the 1971-2006 period of time (Barbosa et al., 2010a) that continuous nowadays. A large part of the swimming research is dedicated to the swimming strokes kinematics. It can be considered that some topics are assessed on regular basis: (i) stroke cycle kinematics; (ii) limbs kinematics; (iii) hip and centre of mass kinematics.

\subsection{Stroke cycle kinematics}

Velocity (v) is the best variable to assess swimming performance. For a given distance, Front Crawl is considered the fastest swim stroke, followed by Butterfly, Backstroke and Breaststroke (Craig et al., 1985; Chengalur \& Brown, 1992).

Swimming velocity can be described by its independent variables: stroke length (SL) and stroke frequency (SF). SL is defined as being the horizontal distance that the body travels during a full stroke cycle. SF is defined as being the number of full stroke cycles performed within a unit of time (strokes.min ${ }^{-1}$ ) or Hertz $(\mathrm{Hz})$. Increases or decreases in $\mathrm{v}$ are determined by combined increases or decreases in SF and SL, respectively (Tousaint et al., 2006; Craig et al., 1985; Kjendlie et al., 2006). Those are polynomial relationships for all swim strokes (Keskinen \& Komi, 1988; Pendergast et al., 2006) (Fig. 1). For Craig and Pendergast (1979) the Front Crawl has the greatest SL and SF in comparison to remaining swimming techniques. Authors suggested similar behavior for the Backstroke except that at a given SF, the SL and v were less than for the Front Crawl. At Butterfly stroke, increases of the v were related almost entirely to increases in SF, except at the highest v. At Breaststroke increasing $\mathrm{v}$ was also associated with increasing in SF, but the SL decreased more than in the other swim strokes (Craig an Pendergast, 1979).

Throughout an event, the decrease of $\mathrm{v}$ is mainly related to the decrease of SL in all swim strokes (Hay \& Guimarães, 1983). There is a "zig-zag" pattern for SF during inter-lap. The maximum SF on regular basis happens at the final lap (Letzelter \& Freitag, 1983).

Comparing the swim strokes by distance, there is a trend for SF and v decrease and a slightly maintenance of SL with increasing distances (Jesus et al., 2011; Chollet et al., 1996). Swimmer must have a high SL and, therefore, v should be manipulated changing the SF (Craig \& Pendergast, 1979).

One other variable often used to assess the stroke cycle kinematics is the stroke index (SI). SI is considered as an estimator for overall swimming efficiency (Costill et al., 1985). This index assumes that, at a given $\mathrm{v}$, the swimmer with greater SL has the most efficient swimming technique. Regarding all the swimming strokes, Front Crawl is the one with the highest SI, followed by Backstroke, Butterfly and Breaststroke (Sánchez \& Arellando, 2002). Analyzing it according to the distance, literature it not completely consensual. Sánchez and Arellano (2002) reported a trend for SI decrease from the 50 to the $400 \mathrm{~m}$ events, except at Breaststroke. On the other hand, Jesus et al. (2011) showed not so obvious decrease in SI from shorter to longer distances in the World Championships finalists. There was only a significant effect of distance in SI for the female swimmers.

\subsection{Limbs kinematics}

Stroke mechanics variables, including the SF and the SL are dependent from the limb's kinematics. That is the reason why some effort is done to understand the contribution of the 
limb's behavior. For instance, at Front Crawl, Deschodt et al. (1996) observed a significant relationship between the hip velocity and the horizontal and vertical motion of the upper limbs. As the upper limb's velocity increased, the horizontal velocity of the swimmers increased as well. Therefore, it can be argued that upper limbs velocity has a major influence in swimming performance. Indeed, Hollander et al. (1988) found a small contribution of the legs to propulsion (approximately 10\%) at Front Crawl. However, Deschodt et al. (1999) reported a relative contribution of about $15 \%$. To the best of our knowledge there is no study about the partial contribution of upper and lower limb's to total swim velocity in the remaining strokes.
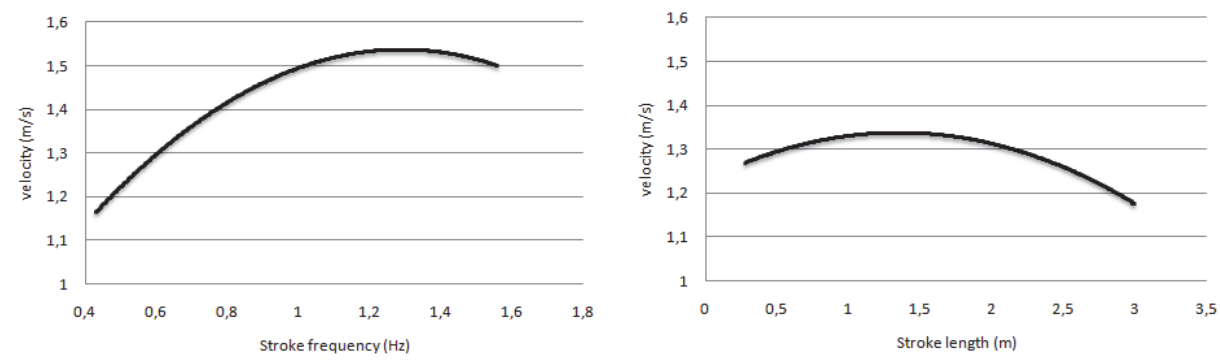

Fig. 1. The relationships between swimming velocity with stroke frequency and stroke length.

At Front Crawl another issue is the contribution of the body roll to the upper limb's kinematics and therefore to swim performance. Some researchers, such as Psycharakis and Sanders (2010), suggest a high contribution of the body roll and its relationship to breathing patterns to the limb's kinematics. A better body roll imposes a pronounced hand's " $S$ " shape trajectory that increases the thrust.

At Backstroke the body roll is also a main issue. Good level swimmers should have a better streamlined position (Maglischo, 2003); plus a large body roll and a higher emphasis in the kicking actions (Cappaert et al., 1996). The " $\mathrm{S}$ " shape of the hand's path is also related to a higher thrust than other kind of trajectories (Ito, 2008).

At Breaststroke, the timing between the upper and lower limbs is a major concern. A significant relationship between upper and lower limbs coordination with swim velocity was verified (Chollet et al., 1999). Tourny et al. (1992) suggested that higher velocities might be achieved reducing the gliding phase. Nowadays, the total time gap between arms and legs propulsive actions is assessed on regular basis to understand this phenomenon (Seifert \& Chollet, 2008).

At Butterfly stroke, main kinematic aspects are the trunk angle, the arm's full extension during the upsweep and the emphasis in the second kick. Higher trunk angle with horizontal plane will increase the projected surface area and the drag force. To decrease it some butterfliers breathe to the side (Barbosa et al., 1999) and others adopt a specific breathing pattern with no breathing in some cycles (Alves et al., 1999; Barbosa et al., 2003).

Butterfliers with increased velocities present a higher extension of the elbow at the upsweep, in order to increase the duration of this propulsive phase (Togashi \& Nomura, 1992). Considering the lower limbs kinematics, the reduction of the kick amplitude plus the 
increase of kick frequency, combined with the increase of the knee's angle during the downbeat, seems to be the best way to increase the swimmer's velocity (Arellano et al., 2003). Barbosa et al (2008a) found that a high segmental velocity of the legs during the downbeats, specially the second one, will decrease the speed fluctuation.

For all swim techniques, several manuscripts had demonstrated the importance of the last phases of the underwater stroke cycle for propulsion (Schleihauf, 1979; Schleihauf et al., 1988). So, higher swim velocities are achieved increasing the partial duration and the propulsive force during the final actions of the underwater curvilinear trajectories (Fig. 2).

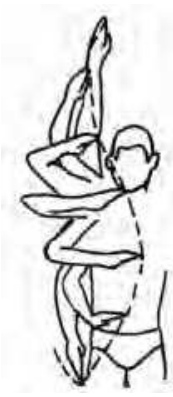

A

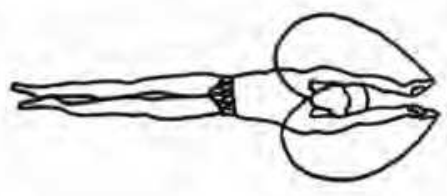

C

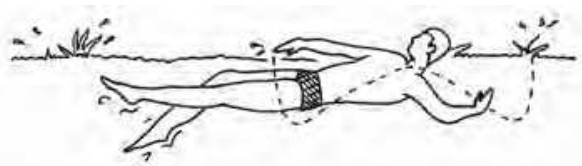

B

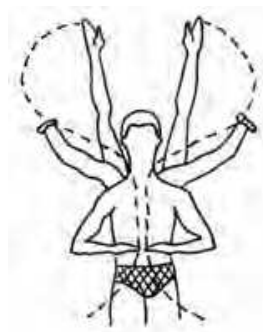

$\mathrm{D}$

Fig. 2. The hand's underwater path at Front Crawl (panel A), Backstroke (panel B), Breaststroke (panel C) and Butterfly stroke (panel D).

\subsection{Hip and centre of mass kinematics}

Hip and/or centre of mass are considered as a way to analyze the body's kinematics. However, the hip is not validated as an appropriate estimator of the centre of mass kinematics (Mason et al., 1992; Barbosa et al., 2003; Psycharakis \& Sanders 2009). The hip intra-cyclic velocity presents more variations than the centre of mass. Besides, the peaks and troughs do not temporally coincide throughout the stroke cycle. Inter-limbs actions during the stroke cycle constantly change the centre of mass position (Psycharakis \& Sanders, 2009). The hip is not able to represent such variations since it is a fixed anatomical landmark. Although this bias, the assessment of the anatomical landmark is still an option for some research groups.

The most often assessed variable related to the hip and/or the centre of mass is the intra-cyclic variation of the horizontal velocity $(\mathrm{dV})$. Throughout the stroke cycle, the body's velocity is not uniform. There are increases and decreases of the body's velocity due to the limb's actions. Indeed, the $\mathrm{dV}$ has been considered as one of the most important biomechanical variables to be assessed in competitive swimming (Komolgorov \& Duplisheva, 1992). 
From a mathematical point of view, the $\mathrm{dV}$ is described with non-linear functions. Nevertheless, determination coefficients from those models are moderate, since swimmers present different individual $\mathrm{dV}$ curves. Individual curve present some changes in comparison to mean curves from several subjects, expressing his/her interpretation of the swim technique (Barbosa et al., 2010b).

At Front Crawl, dV has a multi-model profile (Barbosa et al., 2010c) (Fig. 3, panel A). Higher peaks are related to arm's actions and lower peaks to leg's actions. For some individual curve it can be noticed two higher peaks with different velocities. Those peaks are related to the most propulsive phases of each arm. Moreover, it seems that there is for some subjects an asymmetrical application of propulsive force from both arms. A similar trend can be verified for the Backstroke dV's (Fig. 3, panel B).

At Breaststroke, dV is characterized by a bi-modal profile (Barbosa et al., 2010c) (Fig. 3, panel C). One peak is related to arm's actions and the other to the leg's action. Both peaks should be more or less even, but with a higher value for the leg's peak followed. After that peak, the gliding phase happens with a v decrease. Indeed, the gliding phase is another issue to consider regarding the Breaststroke $\mathrm{dV}$. Subjects should know the exact moment to start a new stroke cycle, avoiding a major decrease of the instantaneous v (Capitão et al., 2006).

At Butterfly stroke, dV presents a tri-modal profile (Barbosa et al., 2003) (Fig. 3, panel D). The first peak is due to the leg's first downbeat, a second peak related to the arm's insweep, a last and highest peak during the arm's upsweep. The arm's recovery is a phase when the instantaneous velocity rapidly decreases.

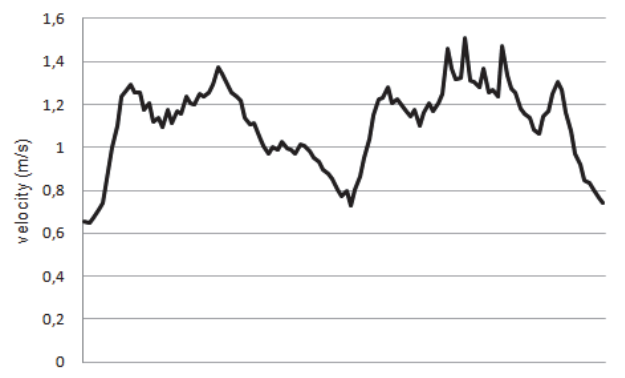

A

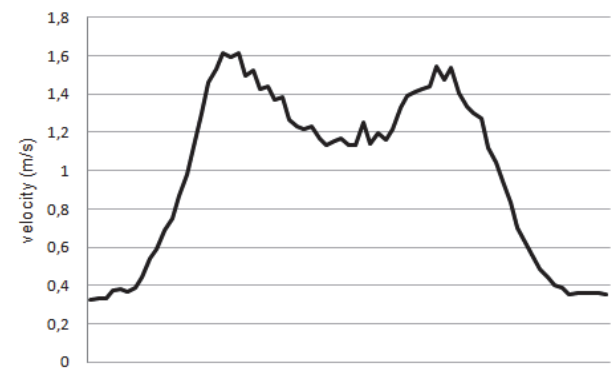

C

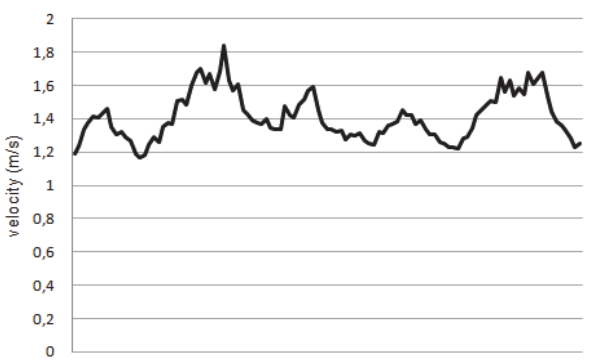

B

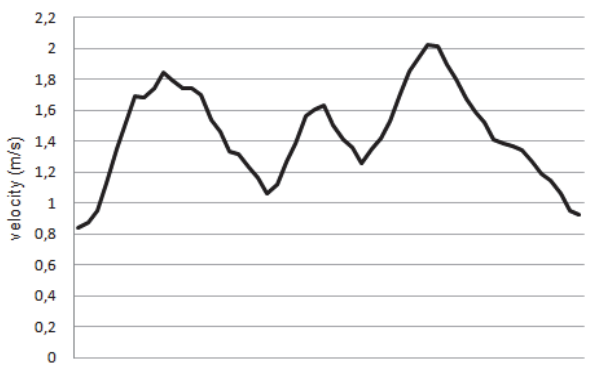

$\mathrm{D}$

Fig. 3. The intra-cyclic variation of the horizontal velocity at Front Crawl (panel A), Backstroke (panel B), Breaststroke (panel C) and Butterfly stroke (panel D). 
There is a relationship between $\mathrm{dV}$ and $\mathrm{v}$, as well as, between $\mathrm{dV}$ and the swimming energy cost. There is a polynomial relationship between $\mathrm{dV}$ and $\mathrm{v}$ in the four competitive swim strokes (Barbosa et al., 2006). The dV increases to a given point with increasing $\mathrm{v}$ and then starts to decrease. So, high velocities seem to impose a lower dV. Added to that, increasing $\mathrm{dV}$ will lead to an increase in the energy cost of swimming, even controlling the effect of the v (Barbosa et al., 2005; 2006). In this sense, in all the four competitive strokes, a low dV leads to higher swim efficiency. For instance, at Breaststroke more pronounced body waving imposed a decreased dV (Persyn et al., 1992; Sanders et al., 1998; Silva et al., 2002). At Butterfly stroke, a low velocity during hand's entry, a high hand's velocity during the upsweep and a high velocity of the second downbeat will decrease the dV (Barbosa et al., 2008). So, some specific limb's actions in each swim stroke are able to decrease the $\mathrm{dV}$ and, therefore, to increase the swim efficiency and by this way enhancing performance.

\section{Competitive swimming strokes kinetics}

For a long time kinetic assessment was made adopting experimental research designs. Since the beginning of the XXth century some research was done to estimate the drag submitted and the propulsion produced by a swimmer. Houssay in 1912, Cureton in 1930 and Karpovich and Pestrecov in 1939 are considered the pioneers in this kind of research (Lewillie, 1983). One hundred years later, in the beginning of the XXIth century, new research trends, based on computational simulation techniques (Bixler \& Riewald, 2002; Bixler et al., 2007; Marinho et al., 2008) and particle image velocimetry (Kamata et al., 2006) have started.

Kinetics analysis in swimming has addressed to understand two main topics of interest: (i) the propulsive force generated by the propelling segments and; (ii) the drag forces resisting forward motion, since the interaction between both forces will influence the swimmer's speed.

\subsection{Propulsive force}

The swimmers' performance is limited by their ability to produce effective propulsive force (the component of the total propulsive force acting in the direction of moving). The measurement of the propulsive forces generated by a swimmer has been of interest to sports biomechanics for many years. Despite the task of directly measuring the propulsive forces acting on a freely swimming subject is practically impossible, Hollander et al. (1986) developed a system for measuring active drag (MAD system) by determining the propulsive force applied to underwater push-off pads by a swimmer performing the Front Crawl arm action only. However, the intrusive nature of the device disables its use during competition and reduces its ecological validity (Payton \& Bartlett, 1995). A non-intrusive method of estimating propulsive hand forces during free swimming was developed by Schleihauf (1979) and was the basis of several studies (Berger et al., 1995; Sanders, 1999). In this method the instantaneous propulsive forces are estimated according to vectorial analysis of forces combination's acting on model hands in an open-water channel and the recordings of underwater pulling action of a swimmer. Using a plastic resin model of an adult human hand, Schleihauf (1979) measured forces for known orientations to a constant water flow, determining drag and lift coefficients for specific orientations. These data were then used together with digitized kinematic data of the hand to estimate the lift, drag and resultant force vectors produced during the stroke cycle of the swimmers. 
The relative contribution of drag and lift forces to overall propulsion is one of the most discussed issues in swimming hydrodynamics research. Regarding the water channel analysis, Schleihauf (1979) reported that lift coefficient values increased up to an attack angle around $40^{\circ}$ and then decreased, although some differences with respect to the sweepback angle were observed. Drag coefficient values increased with increasing the attack angle and were less sensitive to sweepback angle changes. In a more detail analysis, Bixler and Riewald (2002) evaluated the steady flow around a swimmer's hand and forearm at various angles of attack and sweep back angles. Force coefficients measured as a function of angle of attack showed that forearm drag was essentially constant and forearm lift was almost zero (Figs. 4 and 5). Moreover, hand drag presented the minimum value near angles of attack of $0^{\circ}$ and $180^{\circ}$ and the maximum value was obtained near $90^{\circ}$, when the model is nearly perpendicular to the flow. Hand lift was almost null at $95^{\circ}$ and peaked near $60^{\circ}$ and $150^{\circ}$.

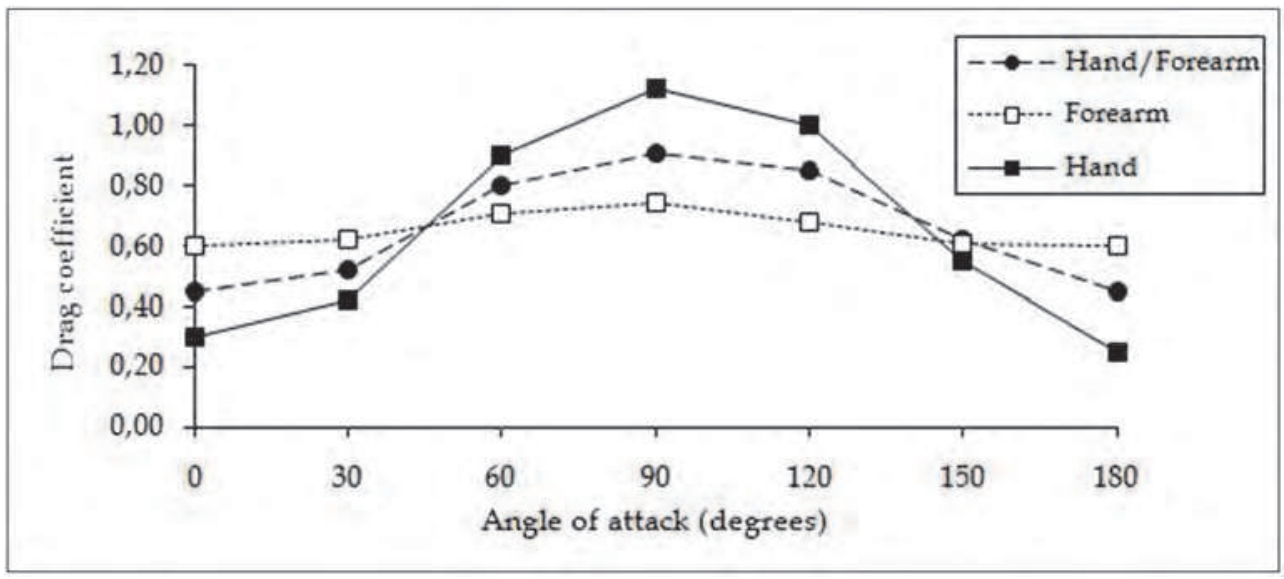

Fig. 4. Drag coefficient $v$ s. angle of attack for the digital model of the hand, forearm and hand / forearm (Sweep back angle $=0^{\circ}$ ). Adapted from Bixler and Riewald (2002).

When the sweep back angle is considered, it is interesting to notice that more lift force is generated when the little finger leads the motion than when the thumb leads (Bixler \& Riewald, 2002; Silva et al., 2008).

Another important issue is related to the contribution of arms and legs to propulsion. It is almost consensual that most of propulsion is generated by the arms' actions. In Front Crawl swimming, it was found (Hollander et al., 1988; Deschodt, 1999) that about 85 to $90 \%$ of propulsion is produced by the arms' movements. Accordingly, the majority of the research under this scope is performed on arm's movements. Nevertheless, leg's propulsion should not be disregarded and future studies under this field should be addressed, helping swimmers to enhance performance. Regarding arms' actions, a large inter-subject range of fingers relative position can be observed during training and competition, regarding thumb position and finger spreading. Although some differences in the results of different studies (Schleihauf, 1979; Takagi et al., 2001; Marinho et al., 2009), main results seemed to indicate that when the thumb leads the motion (sweep back angle of $0^{\circ}$ ) a hand position with the thumb abducted would be preferable to an adducted thumb position. Additionally, Marinho et al. (2009) found, for a sweep back angle of $0^{\circ}$, that the position with the thumb 
abducted presented higher values than the positions with the thumb partially abducted and adducted at angles of attack of $0^{\circ}$ and $45^{\circ}$. At an angle of attack of $90^{\circ}$, the position with the thumb adducted presented the highest value of resultant force.

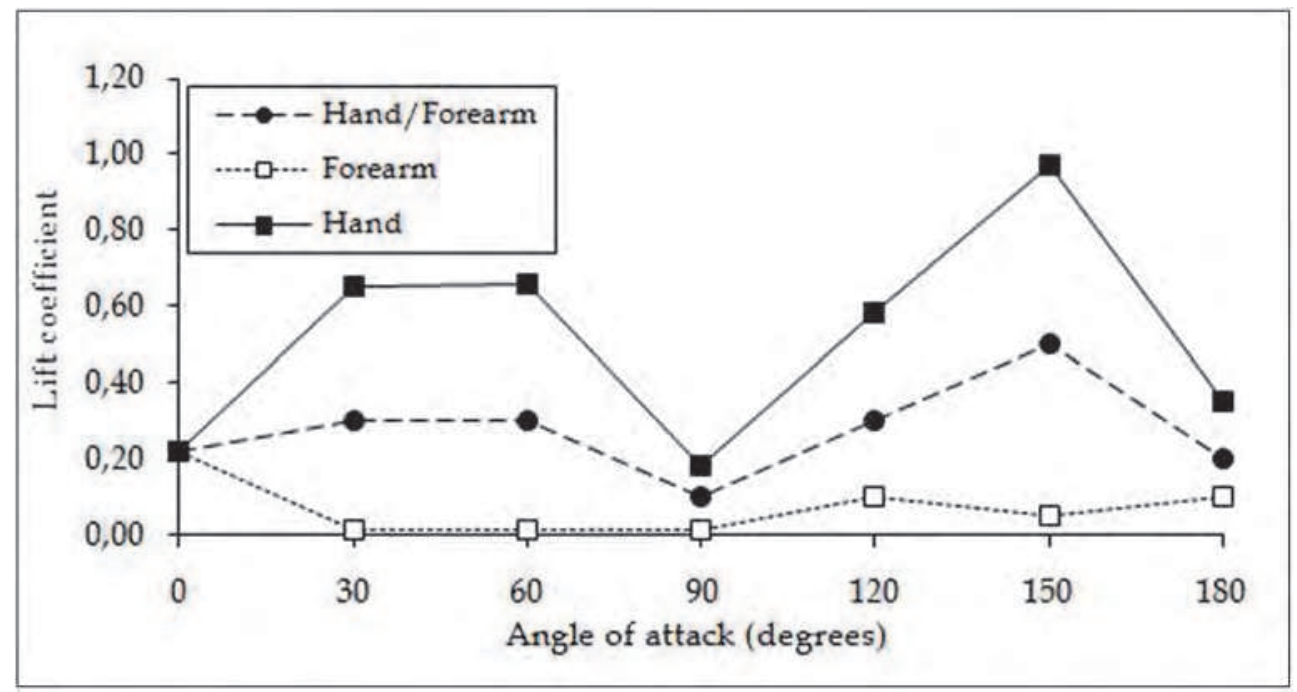

Fig. 5. Lift coefficient $v$ s. angle of attack for the digital model of the hand, forearm and hand / forearm (Sweep back angle $=0^{\circ}$ ). Adapted from Bixler and Riewald (2002).

When considering different finger spreading, Marinho et al. (2010a), using a numerical analysis, studied the hand with: (i) fingers close together, (ii) fingers with little distance spread (a mean intra finger distance of $0.32 \mathrm{~cm}$, tip to tip), and (iii) fingers with large distance spread $(0.64 \mathrm{~cm}$, tip to tip), following the same procedure of Schleihauf (1979) research. Marinho et al. (2010a) found that for attack angles higher than $30^{\circ}$, the model with little distance between fingers presented higher values of drag coefficient when compared with the models with fingers closed and with large finger spread. For attack angles of $0^{\circ}, 15^{\circ}$ and $30^{\circ}$, the values of drag coefficient were very similar in the three models of the swimmer's hand. Moreover, the lift coefficient seemed to be independent of the finger spreading, presenting little differences between the three models. Nevertheless, Marinho et al. (2010a) were able to note slightly lower values of lift coefficient for the position with larger distance between fingers. These results suggested that swimmers to create more propulsive force could use fingers slightly spread.

However, these studies were conducted only under steady state flow conditions and as mentioned above one knows (Schleihauf et al., 1988) that swimmers do not move their arms/hands under constant velocity and direction motions. Therefore, some authors (e.g., Sanders, 1999; Bixler \& Riewald, 2002; Sato \& Hino, 2003; Rouboa et al., 2006) referred that it is important to consider unsteady effects when swimming propulsion is analysed. For instance, Sato and Hino (2003) using also numerical and experimental data showed that the hydrodynamic forces acting on the accelerating hand was much higher than with a steady flow situation and these forces amplifies as acceleration increases. 


\subsection{Drag force}

Regarding the hydrodynamic drag, this force can be defined as an external force that acts in the swimmer's body parallel but in the opposite direction of his movement direction. This resistive force is depending on the anthropometric characteristics of the swimmer, on the characteristics of the equipment used by the swimmers, on the physical characteristics of the water field, and on the swimming technique.

The hydrodynamic drag resisting forward motion $(D)$ can be expressed by Newton's equation:

$$
D=1 / 2 C_{D} \rho S v^{2}
$$

Where $\rho$ represents the fluid density, $C_{D}$ represents the drag coefficient, $S$ represents the projection surface of the swimmer and $v$ represents the swimming velocity.

The evaluation of the intensity of the hydrodynamic drag during swimming represents an important aim in swimming biomechanics. Drag determined by towing a non-swimming subject through the water (passive drag) has been studied for a long time (Karpovich, 1933). However, passive drag analysis does not consider the drag that the swimmer creates when he produces thrust to overcome the drag, i.e., during actual swimming (active drag). Thus, one of the most important parameters in the swimming hydrodynamics scope is to determine the drag of a body that is actively swimming. This assumption resulted in attempts to determine the drag of a person who is actively swimming. Indeed, passive drag is lower than active drag for the same subject (Kjendlie \& Stallman, 2008).

Aiming to achieve this goal, techniques to assess active drag were developed by several research groups in the 70s, based on interpolation techniques (e.g., Clarys \& Jiskoot, 1975; di Prampero et al., 1974). These methods involved indirect calculations based upon changes in oxygen consumption, as additional loads were placed on the swimmer (Marinho et al., 2010b). Later on, Hollander et al. (1986) developed the MAD-system (measurement of active drag), relying on the direct measurement of the push-off forces while swimming the Front Crawl stroke only with arms. In the 90s, Kolmogorov and Duplishcheva (1992) designed another method to determine the active drag: the velocity perturbation method, also known as the method of small perturbations. In this approach, subjects swim a lap twice at maximal effort: (i) free swimming; and (ii) swimming while towing a hydrodynamic body that creates a known additional drag. For both trials, the average velocity is calculated. Under the assumption that in both swims the power output to overcome drag is maximal and constant, drag force can be determined considering the difference in swimming velocity. In contrast to the interpolation techniques and the MAD-system, that required heavy and costly experimental procedures, the velocity perturbation method just required the use of the hydrodynamic body device and a chronometer to assess active drag. Additionally, this approach can be applied to measure active drag in the four competitive strokes. Other methods can only be applied to the Front Crawl (e.g., the MAD-system, Hollander et al., 1986) and the swimmer presents some segmental constrains, since legs are not taken into account, as they are hold by a pull buoy. Using this approach several studies has been conducted to evaluate active drag in swimming (e.g., Kjendlie \& Stallman, 2008; Marinho et al., 2010b). Kjendlie and Stallman (2008) found that active drag in adults was significantly higher than in children. This difference between adults and children was mostly due to the different size and velocity during swimming. Marinho et al. (2010b) also studied active drag comparing boys and girls, reporting that there were no differences between boys and girls. 
A possible explanation may be related to the similar values of body mass and height in boys and girls found in this study. However, girls tended to have lower drag values than boys, which can be also related to the lower velocities achieved by the first ones.

The total drag consists of the frictional, form and wave drag components. Frictional drag is depending on water viscosity and generates shear stress in the boundary layer. The intensity of this component is mainly due to the wetted surface area of the body, the characteristics of this surface and the flow conditions inside the boundary layer. Form drag is the result of a pressure differential between the front and the rear of the swimmer, depending on the velocity, the density of water and the cross sectional area of the swimmer. Near the water surface, due to the interface between two fluids of different densities, the swimmer is constrained by the formation of surface waves leading to wave drag (Toussaint \& Truijens, 2005).

The contribution of form, friction and wave drag components to total drag during swimming is an interesting topic in sports biomechanics. Data available from several experimental studies show some difficulties involved in the evaluation of the contribution of each drag component (Bixler et al., 2007). It is mostly accepted that frictional drag is the smallest component of total drag, especially at higher swimming velocities, although this drag component should not be disregarded in elite level swimmers. Bixler et al. (2007) using numerical simulation techniques found that friction drag represented about $25 \%$ of total drag when the swimmer is gliding underwater. Zaidi et al. (2008) also found an important contribution of friction drag to the total drag when the swimmer is passively gliding underwater. These authors found that friction drag represented about $20 \%$ of the total drag. In this sense, issues such as sports equipments, shaving and the decrease of immersed body surface should be considered with detail, since this drag component seems to influence performance especially during the underwater gliding after starts and turns. In addition, form and wave drag represent the major part of total hydrodynamic drag, thus swimmers must emphasize the most hydrodynamic postures during swimming (Toussaint, 2006; Marinho et al., 2009). Although wave drag represents a huge part of total drag during swimming (Kjendlie \& Stallman, 2008); when gliding underwater there is a tremendous reduction of this drag component. For instance, Lyttle et al. (1999) concluded that there is no significant wave drag when a typical adult swimmer is at least $0.6 \mathrm{~m}$ under the water's surface. Moreover, Vennell et al. (2006) found that a swimmer to avoid wave effects must be deeper than 1.8 and 2.8 chest depths below the surface for velocities of $0.9 \mathrm{~m} \mathrm{~s}^{-1}$ and $2.0 \mathrm{~m} \mathrm{~s}^{-}$ 1 , respectively.

\section{Competitive swimming strokes neuromuscular response}

Since the early sixties some research was done regarding the swimming neuromuscular activity (Ikai et al., 1964). However, for a long time such research was merely qualitative, with a reduce focus quantifying this phenomena. For instance, Ikai et al (1964) qualitatively showed that the bicep braquialis, the triceps braquialis, the deltoid and grand dorsal were highly activate during the strokes. On the other hand, for a quantitative perspective, the authors verified that the elbow extensors presented a higher activation than the elbow flexors at Front Crawl, Breaststroke and Butterfly stroke. Indeed this electromyographic (EMG) assessment from Ikai et al. (1964) was thereafter the basis for the swimming stroke descriptions popularized in some swimming textbooks including the ones from Counsilman (1968) or Catteau and Garrof (1968). In the late sixties a research trend more focus in 
quantifying the EMG signal was started by Lewillie $(1967 ; 1973)$ and followed by Clarys (1983; 1988). Comparing to kinematics and kinetics researches, neuromuscular assessments are the less used approach for competitive swimming.

\subsection{Qualitative assessment}

Qualitative EMG relies on judgment of wave form patterns from neuromuscular activity in graphical demonstration. Based on the visual interpretation of the gross EMG signal it is possible to describe the neuromuscular activation according to the temporal domain. In most circumstances, the bio-signal amplitude and the duration are used as variables for a temporal interpretation. The amplitude is roughly proportionally to the force exerted by the underlying muscle. This relationship can be easily appreciated by viewing the EMG signal in real-time while the intensity of the muscular contraction increases. However, the EMG signal is not an estimation of the muscle force produced. On the other hand, analyzing the duration of muscular activation it is possible to observe whether a muscle is active or inactive. Moreover, it is possible to establish timing patterns for dynamic movements and the co-activation of several opossite muscle groups.

For swimming researchers the main focus relies in understanding the dynamics of neuromuscular activity between strokes during the limbs and trunk actions.

Lewillie (1973) conducted a case study in the four strokes at three conditions (slow, normal, fast). The highest neuromuscular activation was observed for the Butterfly stroke at fast condition. Increasing intensity imposed an increase in the anterior rectum and triceps surae activation for all strokes. Nuber et al. (1986) observed high activation of the supraspinatus, infraspinatus, middle deltoid, and serratus anterior during the recovery phases of the Front Crawl, Breaststroke and Butterfly. On the other hand, the latissimus dorsi and pectoralis major were predominately pull-through phase muscles (Nuber et al., 1986). Latter, similar activation during Front Crawl was reported by Pink et al. (1991) for the pectoralis major and latissimus dorsi to propel the body and for the infraspinatus to externally rotate the arm at middle of the arm's recovery. Authors also observed high activation for the three heads of the deltoid and the supraspinatus during the arm's entry and exit.

A study in breaststrokes demonstrated consistently activation for the serratus anterior and teres minor muscles throughout the stroke cycle (Ruwe et al., 1994). Barthels and Adrian (1971) found a great activity for the rectus abdominus and for the spine erector, suggesting that the trunk movement in Butterfly stroke is associated to the lower limbs action. Concerning the upper lims propulsion, Pink et al (1993) reported that the serratus anterior and the subscapularis maintained a high level of activation, being highly susceptible to fatigue and vulnerable to injury.

\subsection{Quantitative assessment}

The quantitative EMG analyzes the subtle changes on wave form patterns that normally are missed or not appreciated by qualitative EMG. This approach combines graphical interpretation with numerical processing data to describe the neuromuscular activation. The amplitude and duration analysis are improved using several data analysis procedures. On a regular basis, researchers use some quantified variables, including the root mean square (RMS) and threshold models for that purpose in the time domain. The RMS is considered to be the most meaningful technique, since it gives a measure of the power of the signal. Threshold intervals are also helpful because they more clearly demarcate the beginning and 
end of each muscle contraction. Both techniques require the use of automated algorithms that extract and analyze motor unit action potentials. The algorithms can simultaneously identify several different motor units' wave forms from the EMG signal to facilitate the acquisition of more data in less time (Stálber et al., 1996).

One other approach used in the quantitative EMG assessment is the spectral analysis. This approach allows to change the signal from temporal domain to frequency domain. Essentially it gives an evaluation of what contribution each frequency has to the original sign. To evaluate the different frequencies contents of maximal voluntary contraction the usual procedure is to use the Fourier transformation. However, new spectral indices (e.g. FInsmk) have been proposed and considered to be valid, reliable and more sensitive than those traditionally used for competitive swimming Dimitrov, 2006; Figueiredo et al., 2010).

Generally, the mean and median frequencies of the EMG signal decrease with time during a task that induces fatigue. The pratical aplication for spectral analysis in swimming is to study muscle fatigue and its relationship to limb's kinematics. Monteil et al. (1996) analyzing the fatigue at the beginning and at the end of a 400m Front Crawl bout in a flume found a data decrease during the insweep phase followed by an increase during the outsweep. Authors indicated a shift of the force production from the insweep to the outsweep and a decrease of hand velocity during the insweep phase. A similar phenomenon was observed by Aujouannet et al. (2006). EMG spectral parameters of the biceps brachii and triceps brachii demonstrated a shift toward lower frequency before and after a maximal $4 * 50 \mathrm{~m}$ swimming test (Aujouannet et al., 2006). In a fatigue state, the spatial hand path remained unchanged, with a greater duration of the catch, the insweep and the outsweep phases (Aujouannet et al., 2006). A $4{ }^{\star} 100$ Front Crawl test until exhaustion demonstrated larger muscular recruitments obtained during the insweep phase and the antagonist activities increases (Rouard et al., 1997). Caty et al. (2007) found an important stabilization of the wrist and high antagonist flexor and extensor carpi activity during the insweep phase (Caty et al., 2007). On the other hand, in outsweep phase, less stabilization and lower antagonist activities were noted (Caty et al., 2007). Fatigue analysis showed an increase in latissimos dorsi and triceps braquialis during 100m all out Front Crawl (Stirn et al., 2010). When increasing distance to $200 \mathrm{~m}$, the inability to maintain swimming velocity in the last laps was coincident with the increase of the fatigue indices for the flexor carpi radialis, biceps brachii, triceps brachii, pectoralis major, upper trapezius, rectus femoris and biceps femoris (Figueiredo et al., 2010).

\section{Competitive swimming strokes biomechanics and performance}

The main focus of swimming researchers is to enhance performance. From a historic perspective, a large part of the research dedicated to competitive swimming aims to identify variables that determine the performance. This can be considered as an exploratory research trend. Very recently, confirmatory data analysis became another topic of interest. In such research designs, researchers try to understand the relationships between the variables identified in previous researches and model the links among them and performance (Barbosa et al., 2010b).

\subsection{Exploratory research}

With exploratory research the aim is to identify from several biomechanical variables those that are associated or related to the swimming performance. This kind of research has been 
developed based on (Barbosa et al., 2010b): (i) comparing cohort groups; (ii) applying exploratory regression models and; (iii) implementing neural network procedures.

The comparison of cohort groups is done comparing mean values or analyzing the variation of some selected biomechanical variables between different competitive level sub-sample groups. For instance, compare expert versus non-expert swimmers, national level versus international/elite level swimmers or, world championships and Olympic Games finalists versus non-finalists. It is obvious that better competitive level is related to a higher swim velocity. On the other hand, higher swim velocity, from better swimmers, is achieved by an increasing stroke length than remain swimmers (Craig et al., 1985; Vilas-Boas, 1996; Leblanc et al., 2007; Seifert et al., 2007). Higher level swimmers also present a higher efficiency, which is expressed by a higher stroke index (Sánchez et al., 2002; Jesus et al., 2011). During high-standard competitions, world-ranked swimmers already maintain a high stroke length. Therefore their biomechanical strategy to increase the swim velocity is to increase as well the stroke rate (Jesus et al., 2011). At least one study attempted to compare the stroke cycle kinematics between World championships medalists versus remaining finalists. There were no significant differences in the stroke kinematics between medallists and non-medallists. As both cohort groups have a very small gap performance, differences between them might be explained by other variables (Jesus et al., 2011). There are also some limb's kinematics differences according to competitive level. The elite swimmers posses a great strength and power to accelerate through the water. They present a limb's kinematics making them able to apply it effectively. Plus, the same limb's kinematics also aims to maintain a better body streamlining position to reduce drag force (Cappaert et al., 1996). For instance, comparing elite versus non-elite swimmers, participating in world championships and Olympic Games (Cappaert et al., 1996;): (i) the trunk angle is lower and there is a higher elbow extension during the finish phase of the pulling pattern for elite than for non-elite swimmers swimming Butterfly stroke; (ii) there is a higher body roll and a higher emphasis in the kicking for elite backstrokes than non-elite ones; (iii) in Breaststroke, timing between arm's and leg's actions is a key factor as non-elite swimmers sometimes achieve a null body velocity within a stroke cycle; (iv) a higher elbow position is required to achieve higher propulsion and a higher body roll in Front Crawl, as done by elite swimmers in comparison to non-elite. Few studies suggest that better competitive level swimmers also present a lower intra-cyclic variation of the body's swimming velocity (Manley and Atha, 1996; Takagi et al., 2004). This seems consistent in Breaststroke but less obvious in remaining swim strokes and should be clear out in near future.

Another possibility is to develop statistical models to identify the best biomechanical predictors of swimming performance. Stroke length was related to swimming economy (Costill et al., 1985) and this one to swimming performance. One attempted was made to determine the stroke cycle variables that are related to Olympic swimmers performance. However, stroke rate, stroke length and stroke index did not correlated significantly with the performance (Arellano et al., 2001). As reported in the previous paragraph, the arguably best swimmers in the world make it difficult to see trends in these variables on the basis of stroke variations. Some papers report the prediction of children swimming performance. The stroke index for the boys (Saavedra et al., 2003; 2010; Vitor \& Bohem, 2010) and the mean velocity of a 50-m maximal bout for girls were included in the final models (Saavedra et al., 2003). In both genders, from 9 to 22 years-old, for the 50-m freestyle event, increases in the swim velocity happen due to increases in the stroke length and stroke index (Morales et al., 2010). 
Neural network is a somewhat recent approach to solve complex problems to model a given phenomena (Fig. 6). Few attempts were made to apply this data analysis procedure to model swimming performance (Pffier \& Hohmann, in press). Modeling the 400-m freestyle performance in young male swimmers, based on several variables including kinetic and kinematical ones, the estimation error was $7 \pm 7.8 \%$ and for the 200 -m medley performance $1.7 \pm 13.3 \%$ (Silva et al., 2007). Same trend was reported in another couple of papers that included Front crawl and Backstroke techniques, gliding in supine and back positions to predict the 50-m Backstroke (Lobenius, 2003) and the stroke rate, swim velocity to predict the 50-m freestyle event (Hohman \& Seidel, 2010).

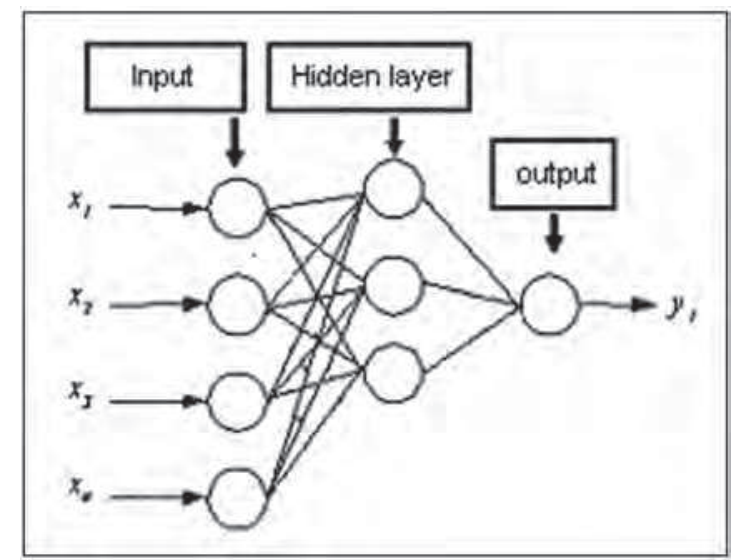

Fig. 6. Example of a performance modeling accomplished by a feed forward neural network with three neurons in a single hidden layer.

\subsection{Confirmatory research}

This procedure consists of a mathematical approach for testing and estimating causal relationships using a combination of statistical data and qualitative causal assumptions previously defined by the researcher to be (or not to be) confirmed. This approach rather than to identify variables, suggests the kind of interplay existing among them (Barbosa et al., 2010d). Hence, structural equating modeling allows analyzing the hypothetical relationships between several biomechanical variables with swim performance and the model's good-of-fit. Indeed this approach is often used on other scientific domains although it is not so popular in the sport's performance, including competitive swimming. To the best of our knowledge this procedure only was applied for young swimmers.

One paper reported the development of a path-flow analysis model for young male swimmers' performance based on biomechanical and energetics variables (Fig. 7). The model included variables such as the stroke length, stroke rate, stroke index, and swim velocity. The confirmatory model explained $79 \%$ of the $200-\mathrm{m}$ freestyle performance and being suitable of the theory presented (Barbosa et al., 2010d). One other study developed a structural equation modeling for active drag force based on anthropometric, hydrodynamic (i.e., frontal surface area, drag coefficient) and biomechanical variables (i.e., stroke length, stroke rate and swim velocity) in young boys (Barbosa et al., 2010e). The confirmatory model explained $95 \%$ of the active drag after the elimination of the frontal surface area. 
Main limitation of the model is related to the frontal surface area estimation equation that does not fit in the model. The confirmatory model included all selected anthropometrical variables, prone gliding test, stroke length, stroke frequency and velocity. Final model excluded the vertical buoyancy test. The confirmatory path-flow model good-of-fit was considered as being very close to the cut-off value, but even so not suitable of the theory. Vertical buoyancy and prone gliding tests are easy and cheap procedures to assess swimmer's kinetics. However, both procedures are not the best techniques to assess the swimmer's hydrostatic and hydrodynamic profile, respectively. Hohmann and Seidel (2010) predicted $41 \%$ of girl's $50-\mathrm{m}$ freestyle performance based on psychological, technique (i.e., stroke rate, swim velocity, limb's coordination), physical conditioning and anthropometrical variables.

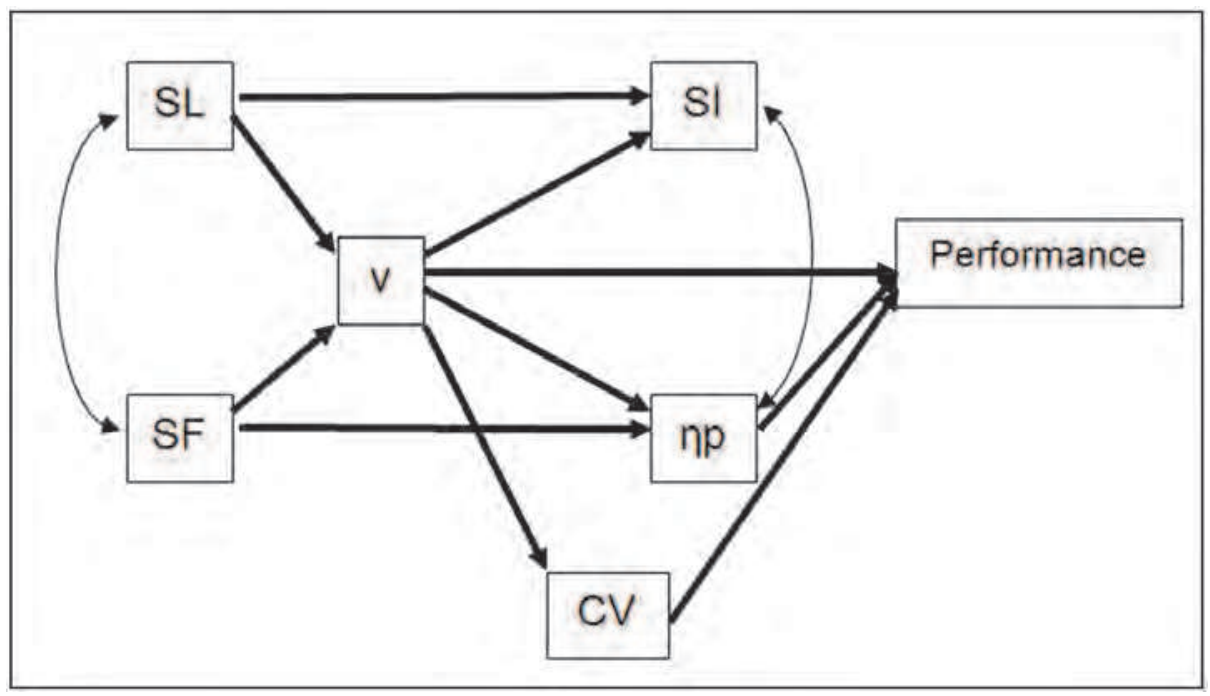

Fig. 7. The final confirmatory model about the relationship between biomechanics, energetics and swimming performance. The model includes the stroke length (SL), stroke frequency (SF), swimming velocity (v), stroke index (SI), propulsive efficiency ( $\eta$ p), critical velocity $(\mathrm{CV})$ and performance.

\section{Conclusion}

There are several biomechanical variables determining the competitive swimmer's performance. For instance, some of those are kinematics variables (e.g., stroke length, stroke frequency, speed fluctuation, limbs' kinematics), kinetics variables (e.g., propulsive drag, lift force, drag force) and neuromuscular variables.

Attempts are being made nowadays to understand the links between all these variables and how it is possible to enhance performance manipulating it. Some models about these relationships are already at the disposal of practitioners. Moreover, a great effort is done by researchers and coaches to assess, to compare and to manipulate these variables from times to times to define goals, establish milestones in the periodization program or even predict the swimmers performance. 


\section{References}

Alves, F.; Cunha, P. \& Gomes-Pereira, J. (1999). Kinematic changes with inspiratory actions in butterfly swimming, In: Biomechanics and Medicine in Swimming VIII, K.L. Keskinen, P.V. Komi \& P.A. Hollander, (Eds.), 9-14, Gummerus Printing, Jyvaskyla

Aujouannet, Y.A.; Bonifazi, M.; Hintzy, F.; Vuillerme, N. \& Rouard, A.H. (2006). Effects of a high-intensity swim test on kinematic parameters in high-level athletes. Applied Physiology Nutrition and Metabolism, 3, 150-158

Barbosa, T.M.; Sousa, F. \& Vilas-Boas, J.P. (1999). Kinematical modifications induced by the introduction of the lateral inspiration in butterfly stroke, In: Biomechanics and Medicine in Swimming VIII, K.L. Keskinen, P.V. Komi \& P.A. Hollander, (Eds.), 1519, Gummerus Printing, Jyvaskyla

Barbosa, T.M.; Santos Silva, J.; Sousa, F. \& Vilas-Boas, J.P. (2003). Comparative study of the response of kinematical variables from the hip and the center of mass in butterfliers, In: Biomechanics and Medicine in Swimming IX, J.C. Chatard, (Ed.), 93-98, University of Saint-Etienne, Saint-Etienne

Barbosa, T.; Keskinen, K.L.; Fernandes, R.J.; Colaço, P.; Lima, A.B. \& Vilas-Boas, J.P. (2005). Energy cost and intracyclic variation of the velocity of the centre of mass in butterfly stroke. European Journal of Applied Physiology, 93, pp. 519-523

Barbosa, T.M.; Lima, F.; Portela, A.; Novais, D.; Machado, L.; Colaço, P.; Gonçalves, P.; Fernandes, R.J. \& Vilas-Boas, J.P. (2006). Relationships between energy cost, swimming velocity and speed fluctuation in competitive swimming strokes, In: Biomechanics and Medicine in Swimming X, J.P. Vilas-Boas, F. Alves \& A. Marques (Eds.), 192-194, Portuguese Journal of Sport Science, Porto

Barbosa, T.M.; Fernandes, R.J.; Morouço, P. \& Vilas-Boas, J.P. (2008). Predicting the intracyclic variation of the velocity of the centre of mass from segmental velocities in butterfly stroke: a pilot study. Journal of Sports Science \& Medicine, 7, pp. 201-209

Barbosa, T.M.; Pinto, E.; Cruz, A.M.; Marinho, D.A.; Silva, A.J.; Reis, V.M.; Costa, M.J. \& Queirós, T.M. (2010a). The Evolution of Swimming Science Research: Content analysis of the "Biomechanics and Medicine in Swimming" Proceedings Books from 1971 to 2006, In: Biomechanics and Medicine in Swimming XI, P.L., Kjendlie, R.K. Stallman \& J. Cabri (Eds.), 312-314, Norwegian School of Sport Sciences, Oslo

Barbosa, T.M.; Bragada, J.A.; Reis, V.M.; Marinho, D.A.; Carvalho, C. \& Silva, J.A. (2010b). Energetics and biomechanics as determining factors of swimming performance: updating the state of the art. Journal of Science and Medicine in Sports, 13, pp. 262-269

Barbosa, T.M.; Silva, A.J.; Reis, A.M.; Costa, M.J.; Garrido, N.; Policarpo, F. \& Reis, V.M. (2010c). Kinematical changes in swimming front crawl and breaststroke with the AquaTrainer (R) snorkel. European Journal of Applied Physiology, 109, pp. 1155-1162

Barbosa, T.M.; Costa, M.J.; Coelho, J.; Moreira, M. \& Silva, A.J. (2010d). Modeling the links between young swimmer's performance: energetic and biomechanics profile. Pediatric Exercise Science, 22, pp. 379-391

Barbosa, T.M.; Costa, M.J.; Marques, M.C.; Silva, A.J. \& Marinho, D.A. (2010e). A model for active drag force exogenous variables in young swimmers. Journal of Human Sports $\mathcal{E}$ Exercise, 5, pp. 379-388

Barthels, K.M. \& Adrina, M.J. (1971). Variability in the dolphin kick under four conditions. In: First International Symposium on "Biomechanics in Swimming, Waterpolo and Diving, 
L. Lewillie \& J.P. Clarys, (Eds.), 105-118. Université Libre de Bruxelles, Laboratoire de L'effort. Bruxelles.

Berger, M.A.M.; de Groot, G. \& Hollander, P. (1995). Hydrodynamic drag and lift forces on human hand/arm models. Journal of Biomechanics, 28, pp. 125-133

Bixler, B.S. \& Riewald, S. (2002). Analysis of swimmer's hand and arm in steady flow conditions using computational fluid dynamics. Journal of Biomechanics, 35, pp. 713717.

Bixler, B.; Pease, D. \& Fairhurst, F. (2007). The accuracy of computational fluid dynamics analysis of the passive drag of a male swimmer. Sports Biomechanics, 6, pp. 81-98

Capitão F, Lima AB, Gonçalves P, Morouço P, Silva M, Fernandes R, Vilas-Boas JP. 2006. Videogrametrically and acelorimetrically assessment intra-cyclic variations of the velocity in breaststroke, In: Biomechanics and Medicine in Swimming X, J.P. Vilas-Boas JP, F. Alves F \& A. Marques (Eds.), 212-214, Portuguese Journal of Sport Science, Porto

Catteau, R. \& Garoff, G. (1968). L'enseignement de la natation, Edition vigot, Paris

Cappaert, J.; Pease, D. \& Troup, J. (1996). Biomechanical highlights of world champion and Olympic swimmers. In: Biomechanics and Medicine in Swimming VII, J. Troup, A. Hollander, D. Strasse, S. Trappe, J. Cappaert \& T. Trappe (Eds.), 76-80, E \& FN SPON, London

Caty, V.; Aujouannet, Y.A.; Hintzy, F.; Bonifazi, M.; Clarys, J.P. \& Rouard, A.H. (2007). Wrist stabilisation and forearm muscle coactivation during freestyle swimming. Journal of Electromyography and Kinesiology, 17, 285-291

Chengalur, S. \& Brown, P. (1992). An analysis of male and female Olympic swimmers in the 200m events. Canadian Journal of Sport Science, 17, pp. 104-109

Chollet, D.; Pelayo, P.; Tourney, C. \& Sidney, M. (1996). Comparative analysis of $100 \mathrm{~m}$ and $200 \mathrm{~m}$ events in the four strokes in top level swimmers. Journal of Hum Movement Studies, 31, pp. 25-37

Chollet, D.; Tourny-Chollet, C. \& Gleizes, F. (1999). Evolution of co-ordination in fl at breaststroke in relation to velocity, In: Biomechanics and Medicine in Swimming VIII, K.L. Keskinen, P.V. Komi \& P.A. Hollander, (Eds.), 29-32, Gummerus Printing, Jyvaskyla

Clarys, J.P. \& Jiskoot, J. (1975). Total resistance of selected body positions in the front crawl, In: Swimming II. J.P. Clarys \& L. Lewillie, (Eds.), 110-117, University Park Press, Baltimore

Clarys, J.P. (1983). A review of EMG in Swimming: explanation of facts and/or feedback information. In: Biomechanics and Medicine in Swimming, A.P. Hollander, P.A. Huijing \& G. de Groot (Eds.), 123-135. Human Kinetics Publishers, Illinois

Clarys, J.P. (1988). The Brussels Swimming EMG project. In: Swimming Science V, B. Ungerechts, K. Wilke \& K. Reischle (Eds.), 157-172, Human Kinetics Books, Illinois

Costill, D.; Kovaleski, J.; Porter, D.; Fielding, R. \& King, D. (1985). Energy expenditure during front crawl swimming: predicting success in middle-distance events. International Journal of Sports Medicine, 6, pp. 266-270

Counsilman, J. (1968). The Science of Swimming. Prentice Hall. Englewood Cliffs, New york.

Craig, A. \& Pendergast, D. (1979). Relationships of stroke rate, distance per stroke and velocity in competitive swimming. Medicine and Science Sports Exercise, 11, pp. 278283 
Craig, A.; Skehan, P.; Pawelczyk, J. \& Boomer W. (1985). Velocity, stroke rate and distance per stroke during elite swimming competition. Medicine and Science Sports Exercise, 17, pp. 625-634

Deschodt V, Rouard A, Monteil K (1996). Relationship between the three coordinates of the upper limb joints with swimming velocity. In: Troup JP, Hollander AP, Strasse D, Trappe SW, Cappaert JM, Trappe TA (Eds). Biomechanics and Medicine in Swimming VII. London: E \& FN Spon, 52-58.

Deschodt, V. (1999). Relative contribution of arms and legs in human to propulsion in $25 \mathrm{~m}$ sprint front crawl swimming. European Journal of Applied Physiology, 80, pp. 192-199

Dimitrov, G.V.; Arabadzhiev, T.I.; Mileva, K.N.; Bowtell, J.L.; Crichton, N. \& Dimitrova, N.A. (2006). Muscle fatigue during dynamic contractions assessed by new spectral indices. Medicine Science and Sports Exercise, 38, 1971-1979

Di Prampero, P.E.; Pendergast, D.R.; Wilson, D.W. \& Rennie, D.W. (1974). Energetics of swimming in man. Journal of Applied Physiology 37, pp. 1-5

Figueiredo, P.; Sousa, A.; Goncalves, P.; Pereira, S.M.; Soares, S.; Vilas-Boas, J.P. \& Fernandes, R.J. (2010). Biophysical Analysis of the 200m Front Crawl Swimming: a Case Study. In: Biomechanics and Medicine in Swimming XI, P.L., Kjendlie, R.K. Stallman \& J. Cabri (Eds.), 79-81, Norwegian School of Sport Sciences, Oslo

Hay, J. \& Guimarães, A. (1983). A quantitative look at swimming biomechanics. Swimming Technique, 20, pp. 11-17

Hohmann, A. \& Seidel, I. (2010). Talent Prognosis in Young Swimmers, In: Biomechanics and Medicine in Swimming XI, P.L., Kjendlie, R.K. Stallman RK \& J. Cabri (Eds.), 262-264, Norwegian School of Sport Sciences, Oslo

Hollander, A.P. ; de Groot, G. ; Van Ingen Schenau, G.L. ; Toussaint, H.M. ; de Best, H. \& Peeters, W. (1986). Measurement of active drag during crawl arm stroke swimming. Journal of Sports Sciences, 4, pp. 21-30

Hollander, A.P., de Groot, G., van Ingen Schenau, G., Kahman, R. \& Toussaint, H. (1988) Contribution of thr legs to propulsion in Front Crawl swimming. In: Swimming Science V, B. Ungerechts, K. Wilke \& K. Reischle, (Eds.), 39-43, Human Kinetics Books, Illinois

Ikai, M.; Ishii, K. \& Miyashita, M. (1964). An electromyographic study of Swimming. Journal of Physical Education, 7, pp. 47-54

Ito, S. (2008). Analysis of the optimal arm stroke in the backstroke. In: The Book of Proceedings of the 1st International Scientific Conference of Aquatic Space Activities, T. Nomura \& B.E. Ungerechts, (Eds.), 362-367, University of Tskuba, Tskuba

Jesus, S.; Costa, M.J.; Marinho, D.A.; Garrido, N.D.; Silva, A.J. \& Barbosa, T.M. (20010). 13th FINA World Championship finals: stroke kinematics and race times according to performance, gender and event, In: Proceedings of the International Symposium in Biomechanics of Sports, J.P. Vilas-Boas, \& A. Veloso, (Eds.), Portuguese Journal of Sport Science, Porto

Lyttle, A.D.; Blanksby, B.A.; Elliott, B.C. \& Lloyd, D.G. (1999). Optimal depth for streamlined gliding, In: Biomechanics and Medicine in Swimming VIII, K.L. Keskinen, P.V. Komi \& P.A. Hollander, (Eds.), 165-170, Gummerus Printing, Jyvaskyla

Kamata E, Miwa T, Matsuuchi K, Shintami H, Nomura T. Analysis of sculling propulsion mechanism using two-components particle image velocimetry. In: Vilas-Boas JP, 
Alves F, Marques A, editors. Biomechanics and Medicine in Swimming X. Porto: Portuguese Journal of Sports Sciences; 2006. Supl 2: 50-52

Karpovich, P. (1933). Water resistance in swimming. Research Quarterly, 4, pp. 21-28

Keskinen, K.L. \& Komi, P.V. (1988). The stroking characteristics in four different exercises in freestyle swimming. In: Biomechanics XI-B, G. de Groot, P.A. Hollander , P. Huijing \& G. van Ingen Schenau, (Eds.), 839-843, Free University Press, Amsterdam

Kjendlie, P.L.; Haljand, R.; Fjortoft, O. \& Stallman RK. (2006). Stroke frequency strategies of international and national swimmers in 100-m races In: Biomechanics and Medicine in Swimming X, J.P. Vilas-Boas JP, F. Alves F \& A. Marques (Eds.), 52-54, Portuguese Journal of Sport Science, Porto

Kjendlie, P.L. \& Stallman, R. (2008). Drag characteristics of competitive swimming children and Adults. Journal of Applied Biomechanics 24, pp. 35-42

Kolmogorov, S. \& Duplischeva, O. (1992). Active drag, useful mechanical power output and hydrodynamic force coeffi cient in different swimming strokes at maximal velocity. Journal of Biomechanics, 25, pp. 311-318

Leblanc H, Seifert L, Tourny-Chollet C, Chollet D. Intra-cyclic distance per stroke phase, velocity fluctuation and acceleration time ratio of a breaststroker's hip: a comparison between elite and non elite swimmers at different race paces. Int $J$ Sports Med 2007; 28:140-147

Letzelter, H. \& Freitag, W. Stroke length and stroke frequency variations in men's and women's 100m freestyle swimming. In: Hollander AP, Huijing PA, de Groot G, editors. Biomechanics and Medicine in Swimming. Illinois: Human Kinetics Publishers; 1983. p.315-322

Lewillie, L. (1967). Analyse télemétrique de l'electromyogramme du nageur. Societé Médicine Belge Education Physique Sport, 20, pp. 174-177

Lewillie, L. (1973). Muscular activity in swimming. In: Biomechanics III, 440-445, Karger, Basel.

Lewillie, L. (1983). Research in swimming: historical and scientific aspects, In: Biomechanics and Medicine in Swimming, A. Hollander, P. Huijing \& G. de Groot, (Eds.), 7-16, Human Kinetics Publishers, Illinois

Lobenius, K. (2003). The employment of regression analysis and neural networks in the prognosis of competitive swimming performance, In: Biomechanics and Medicine in Swimming IX, J.C. Chatard, (Ed.), 545-550, University of Saint-Etienne, Saint-Etienne

Maglischo, E. (2003). Swimming fastest. Human Kinetics Champaign, Illinois

Manley, P. \& Atha J. (1992). Intra-stroke velocity fluctuations in paces breaststroke swimming, In: Biomechanics and Medicine in Swimming VI, D. MacLaren, T. Reilly \& A. Lees, (Eds.), 151-160, E \& FN Spon, London

Marinho, D.A.; Reis, V.M.; Alves, F.B.; Vila-Boas, J.P.; Machado, L.; Rouboa, A.I. \& Silva, A.J. (2008). The analysis of swimming propulsion under unsteady flow conditions. Journal of Sports Science, 26(S1), pp. 10

Marinho, D.A.; Rouboa, A.I.; Alves, F.B.; Vilas-Boas, J.P.; Machado, L.; Reis, V.M., \& Silva, A.J. (2009). Hydrodynamic analysis of different thumb positions in swimming. Journal of Sports Science and Medicine, 8, pp. 58-66

Marinho, D.A.; Barbosa, T.M.; Reis, V.M.; Kjendlie, P.L.; Alves, F.B.; Vilas-Boas, J.P.; Machado, L.; Rouboa, A.I. \& Silva, A.J. (2010a). Swimming propulsion forces are enhanced by a small finger spread. Journal of Applied Biomechanics, 26, pp. 87-92 
Marinho, D.A.; Barbosa, T.M.; Costa, M.J.; Figueiredo, C.; Reis, V.M.; Silva, A.J. \& Marques, M.C. (2010b). Can 8-weeks of training affect active drag in age-group swimmers? Journal of Sport Science and Medicine, 9, pp. 71-78

Monteil, K.M.; Rouard, A.H.; Dufour, A.B.; Cappaert, J.M. \& Troup, J.P. (1996). Swimmers'shoulder: EMG of the rotators during a flume test. In: Biomechanics and Medicine in Swimming VII, J. Troup, A. Hollander, D. Strasse, S. Trappe, J. Cappaert \& T. Trappe (Eds.), 83-89, E \& FN SPON, London

Morales, E.; Arellano, R.; Famia, P. \& Mercades J. (2010). Regression Analysis Model Applied to Age-Group Swimmers: Study of Stroke Rate, Stroke Length and Stroke Index, In: Biomechanics and Medicine in Swimming XI, P.L., Kjendlie, R.K. Stallman RK \& J. Cabri (Eds.), 129-132, Norwegian School of Sport Sciences, Oslo

Nuber, G.W.; Jobe, F.W.; Perry, J.; Moynes, D.R. \& Antonelli D. (1986). Fine wire electromyography analysis of muscles of the shoulder during swimming. American journal of Sports Medicine,14, 7-11

Rouboa, A.I.; Silva, A.J.; Leal, L.; Rocha, J. \& Alves, F. (2006). The effect of swimmer's hand/forearm acceleration on propulsive forces generation using computational fluid dynamics. Journal of Biomechanics, 39, pp. 1239-1248

Payton, C., \& Bartlett, R. (1995). Estimating propulsive forces in swimming from threedimensional kinematic data. Journal of Sports Sciences, 13, pp. 447-454

Pendergast, D.R.; Capelli, C.; Craig, A.B.; di Prampero, P.E.; Minetti, A.E.; Mollendorf, J.; Termin, .I.I. \& Zamparo, P. (2006). Biophysics in swimming, In: Biomechanics and Medicine in Swimming X, J.P. Vilas-Boas, F. Alves \& A. Marques (Eds.), 185-189, Portuguese Journal of Sport Science, Porto

Persyn, U.; Colman, V. \& van Tilborg, L. (1992). Movement analysis of flat and undulating breaststroke patterns, In: Biomechanics and Medicine in Swimming VI, D. MacLaren, T. Reilly \& A. Lees, (Eds.), 75-80, E \& FN Spon, London

Pfeiffer, M. \& Hohmann A. (2011). Applications of neural networks in training science. Human Movement Science, Epub ahead of print

Pink, M.; Perry, J.; Browne, A.; Scovazzo, M.L. \& Kerrigan, J. (1991). The normal shoulder during freestyle swimming. An electromyographic and cinematographic analysis of twelve muscles. American journal of Sports Medicine, 19, 569-576

Psycharakis, S.G. \& Sanders, R.H. (2009) Validity of the use of a fixed point for intracycle velocity calculations in swimming. Journal of Science and Medicine in Sport, 12, pp. $262-526$

Psycharakis, S.G. \& Sanders, R.H. (2010). Body roll in swimming: a review. Journal of Sports Science, 28, pp. 229-236

Rouard, A.H.; Billat, R.P.; Deschodt, V. \& Clarys, J.P. (1997). Muscular activations during repetitions of sculling movements up to exhaustion in swimming. Archives of Physiology and Biochemistry, 105, 655-662

Ruwe, P.A.; Pink, M.; Jobe, F.W.; Perry, J. \& Scovazzo, M.L. (1994). The normal and the painful shoulders during the breaststroke. Electromyographic and cinematographic analysis of twelve muscles. American journal of Sports Medicine, 22, 789-796

Sánchez, J. \& Arellano, R. (2002). Stroke index values according to level, gender, swimming style and event race distance, In: Proceedings of the XXth International Symposium on Biomechanics in Sports, K. Gianikellis, (Ed.), 56-59, Universidad de Extremadura, Cáceres 
Sanders, R.; Cappaert, J. \& Pease, D. (1998). Wave characteristics of Olympic breaststroke swimmers. Journal of Applied Biomechanics, 14, pp. 40-51

Saavedra, J.; Escalante, Y. \& Rodriguez, F. (2003). Multidimensional evaluation of peripubertal swimmers: multiple regression analysis applied to talent selection, In: Biomechanics and Medicine in Swimming IX, J.C. Chatard, (Ed.), 551-556, University of Saint-Etienne, Saint-Etienne

Saavedra, J.M.; Escalante, Y. \& Rodríguez, F.A. (2010). A multivariate analysis of performance in young swimmers. Pediatric Exercise Science, 22, pp. 135-151

Sanders, R.H. (1999). Hydrodynamic characteristics of a swimmer's hand. Journal of Applied Biomechanics, 15, pp. 3-26

Sato, Y. \& Hino, T. (2003). Estimation of thrust of swimmer's hand using CFD, In: Proceedings of second international symposium on aqua bio-mechanisms, 81-86, Honolulu

Schleihauf, R.E. (1979). A hydrodynamic analysis of swimming propulsion, In: Swimming III, J. Terauds \& E.W. Bedingfield, (Eds.), 70-109, University Park Press, Baltimore

Seifert, L. ; Chollet, D. \& Chatard, J.C. (2007). Kinematic change during a 100-m Front Crawl: effects of performance level and gender. Medicine Science Sports Exercise, 39, pp. 1784-1793

Seifert, L. \& Chollet, D. (2008). Inter-limb coordination and constraints in swimming: a review. In: Physical Activity and Children, N.P. Beaulieu, (Ed.), 65-93, Nova Science Publishers, New York

Silva, A.J.; Colman, V.; Soons, B.; Alves, F. \& Persyn, U. (2002). Movement variables important for effectiveness and performance in breaststroke, In: Proceedings of the XXth International Symposium on Biomechanics in Sports, K. Gianikellis, (Ed.), 39-42, Universidad de Extremadura, Cáceres

Silva, A.J.; Costa, A.M.; Oliveira, P.M.; Reis, V.M.; Saavedra, J.; Perl, J.; Rouboa, A.I. \& Marinho, D.A. (2007). The use of neural network technology to model swimming performance. Journal of Sports Science \& Medicine, 6, pp. 117-125

Silva, A.J.; Marinho, D.A.; Reis, V.M.; Alves, F.B.; Vilas-Boas, J.P.; Machado, L. \& Rouboa, A.I. (2008). Study of the propulsive potential of the hand and forearm in swimming. Medicine Science and Sport Exercise, 40, pp. S212

Stalber, E.; Nandedkar, S.; Sanders, D. \& Falck, B. (1996). Quantitative motor unit potencial analysis. Journal of Clinical Neurophysiology, 13, 401-422

Stirn I, Jarm T, Kapus V, Strojnik V. 2010. Fatigue Analysis of 100 Meters All-Out Front Crawl Using Surface EMG. In: Biomechanics and Medicine in Swimming XI, P.L., Kjendlie, R.K. Stallman \& J. Cabri (Eds.), 168-170, Norwegian School of Sport Sciences, Oslo

Takagi, H.; Shimizu, Y.; Kurashima, A. \& Sanders, R. (2001). Effect of thumb abduction and adduction on hydrodynamic characteristics of a model of the human hand, In: Proceedings of swim sessions of the XIX international symposium on biomechanics in sports, J. Blackwell \& R. Sanders, (Eds.), 122-126, University of San Francisco, San Francisco

Takagi, H.; Sugimoto, S.; Nishijma, N. \& Wilson, B. (2004). Differences in stroke phases, armleg coordination and velocity fluctuation due to event, gender and performance level in breaststroke. Sports Biomechanics, 3, pp. 15-27

Togashi, T. \& Nomura, T. (1992). A biomechanical analysis of the swimmer using the butterfl $y$ stroke. analysis of the swimmer using the butterfly stroke, In: 
Biomechanics and Medicine in Swimming VI, D. MacLaren, T. Reilly \& A. Lees, (Eds.), 87-91, E \& FN Spon, London

Tourny, C.; Chollet, D.; Micallef, J. \& Macabies, J. (1992). Comparative analysis of studies of speed variations within a breaststroke cycle, In: Biomechanics and Medicine in Swimming VI, D. MacLaren, T. Reilly \& A. Lees, (Eds.), 161-166, E \& FN Spon, London

Toussaint, H. \& Truijens, M. (2005). Biomechanical aspects of peak performance in human swimming. Animal Biology, 55, 1, 17-40

Toussaint, H.; Carol, A.; Kranenborg, H. \& Truijens, M. (2006). Effect of fatigue on stroking characteristics in an arms-only 100-m front-crawl race. Medicine Science Sports Exercise, 38, pp. 1635-1642

Vennell, R.; Pease, D.L. \& Wilson, B.D. (2006). Wave drag on human swimmers. Journal of Biomechanics, 31, pp. 664-671

Vilas-Boas, J.P. (1996). Speed fluctuations and energy cost of different breaststroke techniques. In: Biomechanics and Medicine in Swimming VII, J.P. Troup, A.P. Hollander, D. Strasse, S.W. Trappe, J.M. Cappaert \& T.A. Trappe, (Eds.), 167-171, E \& FN Spon, London

Vitor, Fde.M. \& Böhme, M.T. (2010). Performance of young male swimmers in the 100meters front crawl. Pediatric Exercise Science, 22, pp. 278-87

Zaidi, H.; Taiar, R.; Fohanno, S. \& Polidori, G. (2008). Analysis of the effect of swimmer's head position on swimming performance using computational fluid dynamics. Journal of Biomechanics, 41, pp. 1350-1358 


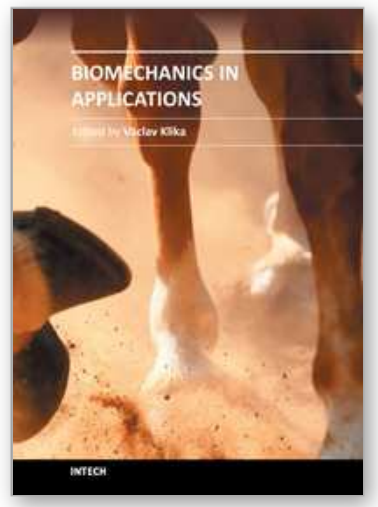

\author{
Biomechanics in Applications \\ Edited by Dr Vaclav Klika
}

ISBN 978-953-307-969-1

Hard cover, 408 pages

Publisher InTech

Published online 09, September, 2011

Published in print edition September, 2011

During last couple of years there has been an increasing recognition that problems arising in biology or related to medicine really need a multidisciplinary approach. For this reason some special branches of both applied theoretical physics and mathematics have recently emerged such as biomechanics, mechanobiology, mathematical biology, biothermodynamics. The Biomechanics in Application is focusing on experimental praxis and clinical findings. The first section is devoted to Injury and clinical biomechanics including overview of the biomechanics of musculoskeletal injury, distraction osteogenesis in mandible, or consequences of drilling. The next section is on Spine biomechanics with biomechanical models for upper limb after spinal cord injury and an animal model looking at changes occurring as a consequence of spinal cord injury. Section Musculoskeletal Biomechanics includes the chapter which is devoted to dynamical stability of lumbo-pelvi-femoral complex which involves analysis of relationship among appropriate anatomical structures in this region. The fourth section is on Human and Animal Biomechanics with contributions from foot biomechanics and chewing rhythms in mammals, or adaptations of bats. The last section, Sport Biomechanics, is discussing various measurement techniques for assessment and analysis of movement and two applications in swimming.

\title{
How to reference
}

In order to correctly reference this scholarly work, feel free to copy and paste the following:

Tiago M. Barbosa, Daniel A. Marinho, Mário J. Costa and António J. Silva (2011). Biomechanics of Competitive Swimming Strokes, Biomechanics in Applications, Dr Vaclav Klika (Ed.), ISBN: 978-953-307-969-1, InTech, Available from: http://www.intechopen.com/books/biomechanics-in-applications/biomechanics-of-competitiveswimming-strokes

\section{INTECH}

open science | open minds

\section{InTech Europe}

University Campus STeP Ri

Slavka Krautzeka 83/A

51000 Rijeka, Croatia

Phone: +385 (51) 770447

Fax: +385 (51) 686166

www.intechopen.com
InTech China

Unit 405, Office Block, Hotel Equatorial Shanghai

No.65, Yan An Road (West), Shanghai, 200040, China

中国上海市延安西路 65 号上海国际贵都大饭店办公楼 405 单元

Phone: +86-21-62489820

Fax: $+86-21-62489821$ 
(C) 2011 The Author(s). Licensee IntechOpen. This chapter is distributed under the terms of the Creative Commons Attribution-NonCommercialShareAlike-3.0 License, which permits use, distribution and reproduction for non-commercial purposes, provided the original is properly cited and derivative works building on this content are distributed under the same license. 